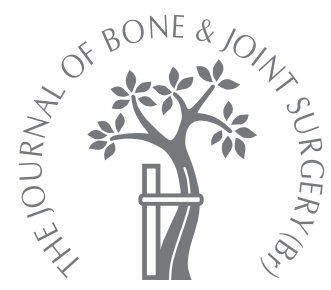

RESEARCH

\title{
Evaluation and comparison of the antimicrobial efficacy of teicoplanin- and clindamycin-coated titanium implants
}

\author{
AN EXPERIMENTAL STUDY
}

S. Aykut,

A. Öztürk,

Y. Özkan,

K. Yanik,

A. A. İlman,

R. M. Özdemir

From Bursa High

Specialty Research

and Training

Hospital, Bursa,

Turkey
S. Aykut, MD, Orthopaedic Surgeon

A. Öztürk, MD, Orthopaedic Surgeon

Y. Özkan, MD, Orthopaedic Surgeon, Associate Professor

R. M. Özdemir, MD

Orthopaedic Surgeon

Clinic of Orthopaedics and

Traumatology

Bursa High Specialty Research and Training Hospital, Yildrim 16630, Bursa, Turkey.

K. Yanik, PhD, Veterinary

Surgeon, Professor

Department of Surgery,

Veterinary Faculty

Uludag University, Görükle,

16059 Nilüfer, Bursa, Turkey.

A. A. İlman, PhD, Veterinary Surgeon

Dogal Yasami Koruma Merkezi,

16059 Nilüfer, Bursa, Turkey.

Correspondence should be sent to $\operatorname{Dr}$ A. Öztürk; e-mail: ozturkalp@mynet.com

(C)2010 British Editorial Society of Bone and Joint Surgery doi:10.1302/0301-620X.92B1. $22134 \$ 2.00$

$J$ Bone Joint Surg $[\mathrm{Br}]$ 2010;92-B:159-63. Received 1 December 2008; Accepted after revision 3 August 2009

We studied the effects of coating titanium implants with teicoplanin and clindamycin in 30 New Zealand White rabbits which were randomly assigned to three groups. The intramedullary canal of the left tibia of each rabbit was inoculated with $\mathbf{5 0 0}$ colony forming units of Staphylococcus aureus. Teicoplanin-coated implants were implanted into rabbits in group 1, clindamycin-coated implants into rabbits in group 2, and uncoated implants into those in group 3. All the rabbits were killed one week later. The implants were removed and cultured together with pieces of tibial bone and wound swabs. The rate of colonisation of the organisms in the three groups was compared.

Organisms were cultured from no rabbits in group 1, one in group 2 but from all in group 3. There was no significant difference between groups 1 and $2(p=1.000)$. There were significant differences between groups 1 and 3 and groups 2 and 3 ( $p<0.001$ ). Significant protection against bacterial colonisation and infection was found with teicoplanin- and clindamycin-coated implants in this experimental model.

Infections associated with internal fixation devices and prostheses occur in between $0.7 \%$ and $4.2 \%$ of elective cases and up to $33 \%$ after high-energy open fractures. ${ }^{1-3}$ Their treatment is challenging, and removal of the device, extensive debridement, long-term use of antibiotics and multiple further operations may be needed. ${ }^{4-6}$

Although antibiotics are widely used in these infections, there may be adverse effects, such as toxicity, insufficient penetration into the bone and joints, and difficulties in monitoring their level. ${ }^{7-9}$ The surface and adjacent surroundings of the implant are difficult to reach with systemic antibiotics and bacteria on the surface of the implant build a biofilm layer to reduce exposure to the antibiotic and the host immune system. ${ }^{10,11}$

In the early 1970s Bucholz and Engelbrecht ${ }^{12}$ mixed antibiotic and polymethylmethacrylate (PMMA) bone cement to treat infection after joint replacement surgery. Experimental studies and clinical trials have compared the use of different antibiotics combined with PMMA. ${ }^{13-16}$ Among other local delivery systems are antibiotic-loaded collagen gauze bands, antibioticloaded bone structured materials and polyurethane implants that can be applied over external fixation pins to avoid pin-track infection. ${ }^{17-20}$ All these methods need a carrier other than the implant itself to release the antibiotic. They may also require a further operation for its removal, as with bone cement spacers. Despite these technical limitations, the local application of antibiotic is widely used, 3,2123 and local delivery by mixing with cement in joint replacement has been successful in cases with a relatively high risk of infection. ${ }^{24,25}$

Studies have recently been published ${ }^{26-31}$ in which implants have been coated with gentamicin, vancomycin and minocycline with rifampicin, thereby preventing the formation of the biofilm over the implant.

This study examined and compared the antimicrobial effectiveness of teicoplanin- and clindamycin-coated titanium wires on an experimental model of Staphylococcus aureus infection.

\section{Material and Methods}

Preparation of antibiotic-covered implants. Titanium wires $2 \mathrm{~mm}$ thick and $35 \mathrm{~mm}$ long were used. Their tips were curved for ease of use. The surfaces of the wires were covered with 200 mesh silica sand under 6 bar pressure. Antibiotic coating was applied directly without using a carrier system. Methanol solutions containing $16 \mathrm{mg} / \mathrm{ml}$ teicoplanin and $12 \mathrm{mg} / \mathrm{ml}$ clindamycin were sprayed directly on to the wires, which had been 
sandblasted and left to dry. The wires were then packed and sterilised by a $25.2 \mathrm{kGy}$ dose of ${ }^{60} \mathrm{Co}$ radiation.

Preparation of the organisms. Methicillin-sensitive ATCC 29123 (American-type culture collection) (MediMark Europe, Grenoble, France) S. aureus lyophilised standard strain was used. It was diluted in broth and plated onto a blood agar plate. This plate was left in an incubator at $37^{\circ} \mathrm{C}$ for 24 hours. The identity of the organism was then checked with an antibiogram (Dade Microscan Walkaway 96, Siemens, Germany) and made ready for surgical inoculation.

Evaluation of the antimicrobial efficiency in vitro. In order to evaluate the antimicrobial activities of the implants in vitro, one wire coated with teicoplanin, one with clindamycin and one uncoated wire were placed in diagnostic sensitivity test medium in which $S$. aureus (ATCC 29123) standard vaccine had been planted 24 hours before and incubated at $37^{\circ} \mathrm{C}$. They were reviewed at 24 and 48 hours, and their effect on growth of organisms assessed.

Preparation of animals and surgery. The local Animal Experimental Ethics Commission approved the study. We used 30 female New Zealand white rabbits whose mean weight was $2.02 \mathrm{~kg}$ (1.22 kg to $3.02 \mathrm{~kg})$. They were chosen randomly and divided into three groups. The operations were conducted under general anaesthesia using $7.5 \mathrm{mg} / \mathrm{kg}$ to 15 $\mathrm{mg} / \mathrm{kg}$ propofol (Abbott) IV following sedation with $3 \mathrm{mg} /$ $\mathrm{kg}$ to $5 \mathrm{mg} / \mathrm{kg}$ Alfazin (Ege Vet) IM. The rabbits were not given prophylactic antibiotics before or after the operation. Before operation the left rear legs of the rabbits were shaved and washed with antiseptic solution, dyed with $10 \%$ polyvinylpyrolidone solution and covered with sterilised drapes. Anaesthetised rabbits were laid supine and a skin incision $1 \mathrm{~cm}$ long was made on the lateral side of the patella of the left knee. After soft-tissue dissection, the tibial plateau was exposed. The intramedullary canal was opened and reamed with a $2 \mathrm{~mm}$ wire. An inoculation of $5 \times 10^{2}$ CFU S. aureus was introduced into the intramedullary canal with a $21 \mathrm{G}$ green needle. The titanium wires were placed in the intramedullary canal. In group 1 the wire had been sprayed with teicoplanin, in group 2 with clindamycin, and in group 3 the wire was uncoated. In order to avoid irritation, the tips of the wires were cut and left under the skin, which was closed with $3 / 0$ monofilament nylon and the wound covered with sterilised gauze. The rectal temperature was taken daily and any rash or discharge in the limb was noted.

Collection of samples for microbiological examination. After one week the rabbits were killed with an intracardiac injection of phenobarbitone. The limbs were prepared for operation and the implant removed and placed in a sterile container. The tibial plateau was excised with a rongeur. Swabs were taken from the site of entrance of the implant and the proximal intramedullary canal. Samples of bone were taken with a rongeur and placed in a sterilised container. A sample of $20 \mathrm{ml}$ of cardiac blood was taken.

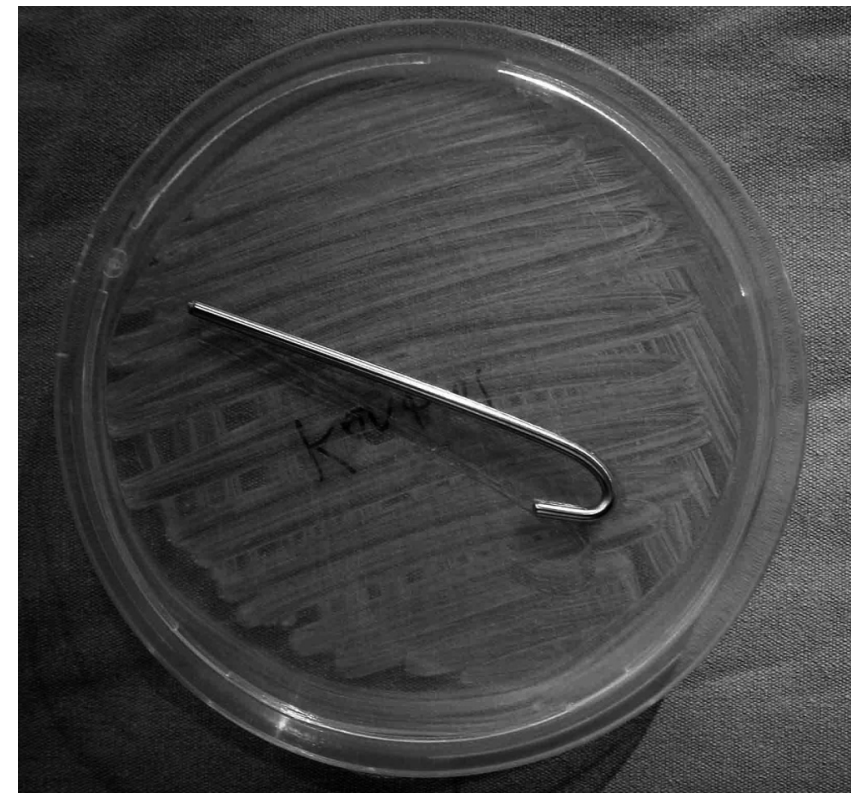

Fig. 1

Photograph showing the control titanium wire on an agar plate with Staphylococcus aureus (American-type culture collection 29123) strain did not produce any zone of inhibition after 48 hours.

Microbiological evaluation. Each implant was placed in $2 \mathrm{ml}$ of a serum solution in a sterile tube and mixed at room temperature with an ultrasonic mixer for ten minutes. Dilutions of 1/10,1/100 and 1/1000 were then inoculated on to blood agar plates. The plates were kept in an incubator at $37^{\circ} \mathrm{C}$ for 48 hours and then their bacterial content was assessed. The samples of bone tissue were put in $2 \mathrm{ml}$ of a serum solution in sterilised tubes and mixed with the ultrasonic mixer for ten minutes at room temperature. Dilutions of $1 / 10,1 / 100$ and $1 / 1000$ were then inoculated onto blood agar plates which were kept in an incubator at $37^{\circ} \mathrm{C}$ for 48 hours, and their bacterial content was then assessed. The swab samples were assessed in a similar manner, as were the blood samples.

Statistical evaluation. Positive cultures were identified and possible contaminants recognised. SPSS for Windows 16.0 (SPSS Inc., Chicago, Illinois) software was used and the means (SD) identified. In cross-table analysis, Pearson's exact and Fisher's exact chi-squared tests were used; $\mathrm{p}<0.05$ was accepted as statistically significant.

\section{Results}

In vitro antimicrobial activity. The presence of $S$. aureus was evaluated in the media culture at 24 and 48 hours. Inhibition of reproduction was observed on the surface and in the surroundings of the wires in the media in which the teicoplanin- and clindamycin-covered wires were placed, but there was considerable growth on the discs where nonantibiotic wires were placed (Figs 1 to 3 ). 


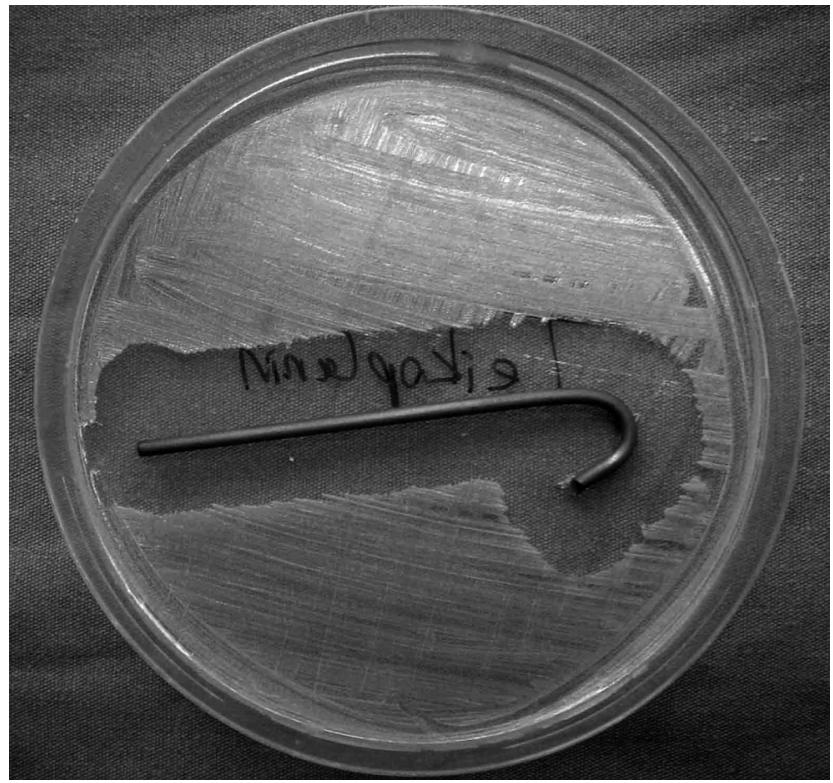

Fig. 2

Photograph showing the teicoplanin-coated titanium wire on an agar plate with Staphylococcus aureus (American-type culture collection 29123) strain produced a zone of inhibition of $15 \mathrm{~mm}$ after 48 hours.

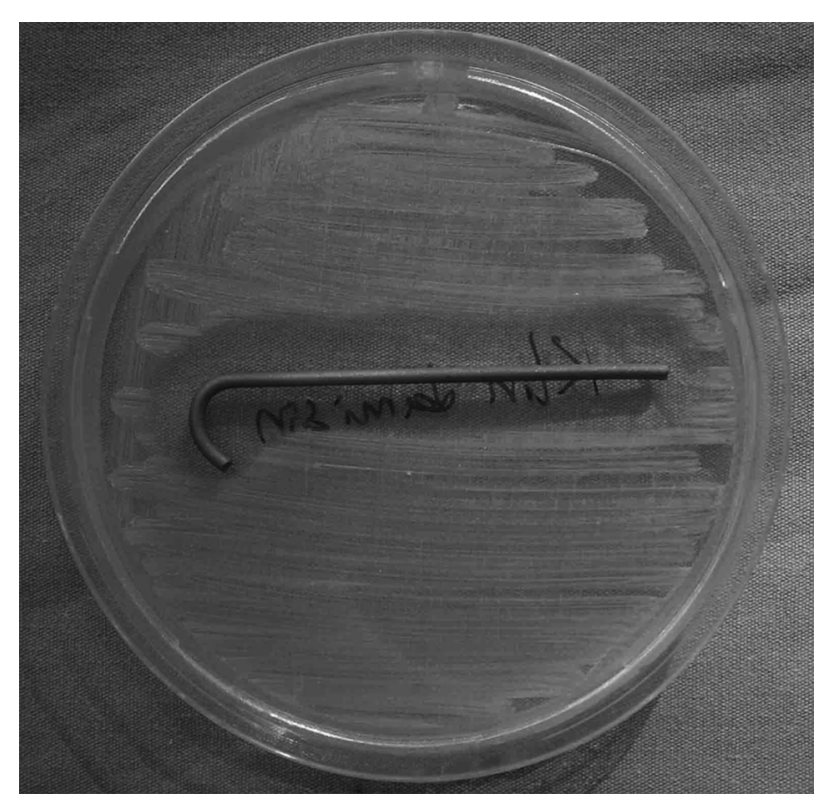

Fig. 3

Photograph showing the clindamycin-coated titanium wire on an agar plate with Staphylococcus aureus (American-type culture collection 29123) strain produced a zone of inhibition of $13 \mathrm{~mm}$ after 48 hours.

Body temperature. No rise in temperature was detected in any of the three groups.

Microbiological assessment. Implant colonisation. Bacterial growth was seen in none of the subjects in group 1, and in one in group 2. Growth occurred in all samples from group 3
Table I. Growth of S. aureus on titanium wires

\begin{tabular}{lccc}
\hline \multirow{2}{*}{ Groups } & \multicolumn{2}{c}{ Bacterial growth } & \\
\cline { 2 - 3 } & Negative & Positive & Total \\
\hline I & 10 & 0 & 10 \\
II & 9 & 1 & 10 \\
III & 0 & 10 & 10 \\
Total & 19 & 11 & 30 \\
\hline
\end{tabular}

Table II. Growth of $S$. aureus on bone tissue

\begin{tabular}{llcl}
\hline \multirow{2}{*}{ Groups } & \multicolumn{2}{l}{$\begin{array}{l}\text { Bacterial growth on bone } \\
\text { tissue }\end{array}$} & \\
\cline { 2 - 3 } & Negative & Positive & Total \\
\hline I & 10 & 0 & 10 \\
II & 9 & 1 & 10 \\
III & 0 & 10 & 10 \\
Total & 19 & 11 & 30 \\
\hline
\end{tabular}

Table III. Growth of S. aureus after swab

\begin{tabular}{lccc}
\hline & \multicolumn{2}{c}{ Bacterial growth } & \\
\cline { 2 - 3 } Groups & Negative & Positive & Total \\
\hline I & 10 & 0 & 10 \\
II & 9 & 1 & 10 \\
III & 0 & 10 & 10 \\
Total & 19 & 11 & 30 \\
\hline
\end{tabular}

(Table I). No meaningful difference was detected between the rates of bacterial growth in the first and second groups (chi-squared Fisher's exact test, $\mathrm{p}=1.000$ ). A statistically meaningful difference was detected between group 1 and group 3, as well as between groups 2 and 3 (chi-squared Fisher's exact test, $\mathrm{p}<0.001$ ).

Bacterial growth on bone tissue. On the samples taken from the left tibia no growth was seen in group 1, in one in group 2 and in all in group 3 (Table II). A statistically meaningful difference was detected between group 1 and group 3, as well as between group 2 and 3 (chi-squared Fisher's exact test, $\mathrm{p}<0.001)$.

Results of swab cultures. No growth was observed in samples from group 1 in the implant entrance and the proximal tibial intramedullary canal. Growth was observed in one subject in group 2, and in all in group 3 (Table III). A statistically meaningful difference was detected between growth in group 1 and group 3 and in group 2 and group 3 (chi-squared Fisher's exact test, $\mathrm{p}<0.001$ ). It was the same rabbit in group 2 that produced growth on the implant, bone tissue and swab culture.

Results of blood culture. A positive blood culture was detected in none of the rabbits.

\section{Discussion}

Antibiotic coating of medical devices has been developed as a potentially effective method for the prevention of infection in implants. ${ }^{32}$ We have shown that teicoplanin- and clindamycin-coated titanium wires can provide protection against colonisation and infection by $S$. aureus, which is 
one of the most common pathogens in such infections. We used the technique described by Darouiche et $\mathrm{al}^{30}$ for antibiotic coating. Our findings indicate that local antibiotic treatment with a carrier is not necessary if the implant is coated with antibiotic. This eliminates the need for a second operation to remove the carrier. S. aureus, which we used as active infective agent, has been isolated from $70 \%$ to $90 \%$ of deep wound infections observed after elective orthopaedic operations, together with coagulase-negative staphylococcus (S. epidermidis). ${ }^{4-6,33}$ Both have a high affinity for bone, accelerate the induction of osteonecrosis and resorb bone matrix. The experimental model we used can be employed in other studies. Darouiche et $\mathrm{al}^{30}$ found implant-related infection in five and osteomyelitis in six of 13 cases in their study in which they used titanium wires covered with minocycline and rifampicin. They also found colonisation of the implant, osteomyelitis and implantrelated infection. They emphasised that a broad-spectrum antibiotic would protect against superinfections, and that the minocycline-rifampicin combination would broaden the spectrum against Gram-negative bacteria. They observed that when the implant was covered with antibiotic a biofilm layer was created which was also effective. An in vitro zone of inhibition that exceeds $10 \mathrm{~mm}$ to $15 \mathrm{~mm}$ is regarded as effective, and has been shown to accurately predict the likelihood of the effectiveness of antibiotic coating against $S$. aureus colonisation and infection in both animal and clinical studies. ${ }^{34-39}$ We observed a zone of inhibition against $S$. aureus of $15 \mathrm{~mm}$ with teicoplanin-coated wire and $13 \mathrm{~mm}$ with clindamycin-coated wire.

Lucke et $\mathrm{al}^{26}$ covered titanium wires with gentamicinloaded poly (D,L-lactide) (PDLLA) and studied in an experimental rat model, the protective effect from implant-related osteomyelitis. They noted that implants covered with PDLLA and $10 \%$ gentamicin reduced implant-related infection effectively. The mean bacterial count of implant cultures in PDLLA and the $10 \%$ gentamicin-covered group was 182 (SD 101) CFU. They stated that with this method implant colonisation was prevented with a high level of antibiotic peri-operatively. Antoci et $\mathrm{al}^{29}$ developed implants attaching vancomycin covalently to titanium wires and studied their protectiveness in a model of infection in the rat thigh. They reported that vancomycin-modified implants were superior to control titanium implants in bacterial colonisation and proliferation.

Teicoplanin is a glycopeptide antibiotic and has a broad spectrum, including Gram-positive aerobic and anaerobic bacteria as well as methicillin-resistant $S$. aureus (MRSA). ${ }^{1,40-43}$ The observation that teicoplanin can penetrate into muscle and bone tissues has made its use parenterally common in bone and joint infections. ${ }^{44}$ It is very effective against all staphylococci, streptococci, enterococci and pneumococci. Its half-life is 88 to 182 hours, and because of this it can be administered parentally in a single dose. ${ }^{45}$ Clindamycin is one of the antibiotics frequently used in local application ${ }^{2,46}$ and is effective against Gram-positive bacteria and Gram-negative anaerobic bacteria. ${ }^{47}$ It pene- trates very well into bone tissue and is successful in the treatment of osteomyelitis. ${ }^{48,49}$ In our study, although destructive osteomyelitis was detected in all cases in the control group and in one case in the clindamycin group, no osteomyelitis was seen in the teicoplanin group. The effects of teicoplanin and clindamycin are more broad and specific than those of minocycline and rifampicin. We consider that teicoplanin is a more appropriate choice for avoiding infection associated with internal fixation devices and prostheses, despite its high cost, because it has high sensitivity and effectiveness against active bacteria. Clindamycin can also be recommended especially when anaerobe organisms are involved.

An ideal animal model will produce an infection rate of $100 \%$ and with low mortality. ${ }^{50}$ These criteria were fulfilled in our study.

Sandblasting increases surface roughness. This technique was applied to the titanium implant to increase its surface for osseointegration. Good bone-to-implant contact was found, ${ }^{51}$ and it is a valuable preparation before antibiotic coating.

Osseointegration is an important requirement in implants such as joint prostheses. In an experimental study, the application of tobramycin to Peri-Apatite-coated titanium foam implants appears to be an effective means of prophylaxis against infection in uncemented implants, and has a beneficial effect on fixation, which will improve long-term survival. ${ }^{52}$ Another study analysing adhesion of osteoblasts to antibioticcoated titanium surfaces showed evidence of greater numbers of osteoblasts on a titanium surface coated with penicillin/ streptomycin. ${ }^{53}$ Hydroxyapatite impregnated with gentamicin has been used as a drug delivery system to eradicate S. aureus. Gentamicin has been shown to have no inhibitory effect on osteointegration. ${ }^{54}$ Antibiotic-impregnated calcium hydroxyapatite ceramic has been used in 18 patients with chronic osteomyelitis. The infection was controlled satisfactorily, and incorporation of the ceramic material into host bone was demonstrated radiographically. ${ }^{55}$

Clindamycin and teicoplanin are both heat-stable antibiotics ${ }^{56,57}$ that can be used with cemented implants. Covering titanium implants with teicoplanin or clindamycin is a useful approach, as it requires no additional material except for the implant itself, and provides excellent protective effects against infections and osteomyelitis.

We thank Dr S. Dilek for her help in microbiologic investigations, and C. Bal for his help in statistical evaluation of the data.

No benefits in any form have been received or will be received from a commercial party related directly or indirectly to the subject of this article.

\section{References}

1. Periti P, Stringa G, Mini E. Comparative multicenter trial of teicoplanin versus cefazolin for antimicrobial prophylaxis in prosthetic joint implant surgery. Eur J Clin Microbiol Infect Dis 1999;18:113-19.

2. Mader JT, Landon GC, Calhoun J. Antimicrobial treatment of osteomyelitis. Clin Orthop 1993;295:87-95.

3. Price JS, Tencer AF, Arm DM, Bohach GA. Controlled release of antibiotics from coated orthopedic implants. J Biomed Mater Res 1996;30:281-6.

4. Bengtson S, Borgquist L, Lindgren L. Cost analysis of prophylaxis with antibiotics to prevent infected knee arthroplasty. BMJ 1989;299:719-20. 
5. Sanderson PJ. Preventing infection in orthopaedic implants. J Antimicrob Chemother 1989;24:277-80.

6. Taylor GJ, Bannister GC, Calder S. Perioperative wound infection in elective orthopaedic surgery. J Hosp Infect 1990;16:241-7.

7. Southorn PA, Plevak DJ, Wright AJ, Wilson WR. Adverse effects of vancomycin administered in the perioperative period. Mayo Clin Proc 1986;61:721-4.

8. Suter F, Avai A, Fusco U, et al. Teicoplanin versus cefamandole in the prevention of infection in total hip replacement. Eur J Clin Microbiol Infect Dis 1994;13:703-6.

9. Wall R, Klenerman L, McCullough C, Fyfe I. A comparison of teicoplanin and cefuroxime as prophylaxis for orthopaedic implant surgery: a preliminary report. J Antimicrob Chemother 1988;21(Suppl):141-6.

10. Gristina AG, Costerton JW. Bacterial adherence to biomaterials and tissue: the sig nificance of its role in clinical sepsis. J Bone Joint Surg [Am] 1985;67-A:264-73.

11. Gristina AG, Oga M, Webb LX, Hobgood CD. Adherent bacterial colonization in the pathogenesis of osteomyelitis. Science 1985;228:990-3.

12. Bucholz HW, Engelbrecht H. Depot effects of various antibiotics mixed with Palacos resins. Chirurg 1970;41:511-15.

13. Bertazzoni Minelli E, Caveiari C, Benini A. Release of antibiotics from polymethylmethacrylate cement. J Chemother 2002;14:492-500.

14. Henry SL, Ostermann PA, Seligson D. The prophylactic use of antibiotic beads in open fractures. J Trauma 1990;30:1231-8.

15. Klemm K. Gentamicin-PMMA beads in treating bone and soft tissue infections. Zentalbl Chir 1979;104:934-42 (in German).

16. Wenke JC, Owens BD, Svoboda SJ, Brooks DE. Effectiveness of commerciallyavailable antibiotic-impregnated implants. J Bone Joint Surg [Br]2006;88-B:1102-4.

17. Forster H, Marotta JS, Heseltine K, Milner R, Jani S. Bactericidal activity of antimicrobial coated polyurethane sleeves for externasl fixation pins. J Orthop Res 2004;22:671-7.

18. Kazimoglu C, Karapinar H, Sener M, et al. In vitro evaluation of gentamicin and teicoplanin release from cancellous human bone. Acta Orthop Traumatol Turc 2008;42:64-9 (in Turkish).

19. Stemberger A, Grimm H, Bader F, Rahn HD, Ascherl R. Local treatment of bone and soft tissue infections with the collagen-gentamicin sponge. Eur J Surg 1997; $578: 17-26$.

20. Orhan Z, Cevher E, Mülazimoglu L, et al. The preparation of ciprofloxacin hydro chloric-loaded chitosan and pectin microspheres: their evaluation in an animal osteomyelitis model. J Bone Joint Surg [Br] 2006;88-B:270-5.

21. Ostermann OA, Henry SL, Seligson D. The role of local antibiotic therapy in the management of compound fractures. Clin Orthop 1993;295:102-11.

22. Evans RP, Nelson CL. Gentamicin-impregnated polymethylmethacrylate beads compared with systemic antibiotic therapy in the treatment of chronic osteomyelitis. Clin Orthop 1992;295:37-42

23. Paley D, Herzenberg JE. Intramedullary infections treated with antibiotic cement rods: preliminary results in nine cases. J Orthop Trauma 2002;16:723-9.

24. Chiu FY, Lin CF, Chen CM, Lo WH, Chaung TY. Cefuroxime-impregnated cement a primary total knee arthroplasty in diabetes mellitus: a prospective, randomised study. J Bone Joint Surg [Br] 2001;83-B:691-5.

25. Liu HT, Chiu FY, Chen CM, Chen TH. The combination of systemic antibiotics and antibiotic impregnated cement in primary total knee arthroplasty in patients of rheumatoid arthritis: evaluation of 60 knees. J Chin Med Assoc 2003;66:533-6.

26. Lucke M, Schmidmaier G, Sadoni S, et al. Gentamicin coating of metallic implants reduces implant-related osteomyelitis in rats. Bone 2003;32:521-31.

27. Lucke M, Wildermann B, Sadoni S, et al. Systemic versus local application of gentamicin in prophylaxis of implant-related osteomyelitis in a rat model. Bone 2005;36:770-8

28. Antoci V Jr, King SB, Jose B, et al. Vancomycin covalently bonded to titanium alloy prevents bacterial colonization. J Orthop Res 2007;25:858-66.

29. Antoci V Jr, Adams CS, Hickok NJ, Shapiro IM, Parvizi J. Antibiotics for loca delivery systems cause skeletal cell toxicity in vitro. Clin Orthop 2007;462:200-6.

30. Darouiche RO, Mansouri MD, Zakarevicz D, AISharif A, Landon GC. In vivo efficacy of antimicrobial-coated devices. J Bone Joint Surg [Am] 2007;89-A:792-7.

31. Montali A. Antibacterial coating systems. Injury 2006;37(Suppl 2):81-6.

32. Abouassaly R, Montague DK, Angermeier KW. Antibiotic-coated medical devices: with an emphasis on inflatable penile prosthesis. Asian J Androl 2004;6:249-57.
33. Zelken J, Wanich T, Gardner M, Griffith $\mathbf{M}$, Bostrom M. PMMA is superior to hydroxyapatite for colony reduction in induced osteomyelitis. Clin Orthop 2007:462:190-4.

34. Darouiche R0. Device-assisted infections: a macroproblem that starts with microadherence. Clin Infect Dis 2001;33:1567-72.

35. Sherertz RJ, Carruth WA, Hampton AA, Byron MP, Solomon DD. Efficacy of antibiotic-coated catheters in preventing subcutaneous staphylococcus aureus infection in rabbits. J Infect Dis 1993;167:98-106.

36. Raad I, Darouiche R, Dupuis J, et al. Central venous catheters coated with minocycline and rifampin for the prevention of catheter-related colonization and bloodstream infections: a randomized, double-blind trial. Ann Intern Med 1997;127:267-74.

37. Chatzinikolaou I, Hanna H, Graviss L, et al. Clinical experience with minocycline and rifampin-impregnated central venous catheters in bone marrow transplantation recipients: efficacy and low risk of developing staphylococcal resistance. Infect Control Hosp Epidemiol 2003;24:961-3

38. Hanna H, Benjamin R, Chatzinikolaou I, et al. Long-term silicone central venous catheters impregnated with minocycline and rifampin decreases rates of catheterrelated bloodstream infection in cancer patients: a prospective randomized clinical trial. J Clin Oncol 2004;22:3163-71

39. Darouiche RO, Berger DH, Khardori N, et al. Comparison of antimicrobial impregnation with tunneling of long-term central venous catheters: a randomized controlled trial. Ann Surg 2005;242:193-200.

40. Periti P, Mini E, Mosconi G. Antimicrobial prophylaxis in orthopedic surgery: the role of teicoplanin. J Antimicrob Chemother 1998;41:329-40.

41. Greenwood D. Microbiological properties of teicoplanin. J Antimicrob Chemother 1998;21(Suppl A):1-13

42. Parenti F, Schito GC, Courvalin P. Teicoplanin chemistry and microbiology. J Chemother 2000;12(Suppl 5):5-14.

43. Shea KW, Cunha BA. Teicoplanin. Med Clin North Am 1995;79:833-44

44. Drago L, De Vecchi E, Fassina MC, Gismondo MR. Serum and bone concentrations of teicoplanin and vancomycin: study in an animal model. Drugs Exp Clin Res 1998;24:185-90.

45. Campoli-Richards DM, Brogden RN, Faulds D. Teicoplanin: a review of its antibacterial activity, pharmacokinetics properties and therapeutic potential. Drugs 1990;40:449-86

46. Naal FD, Salzmann GM, von Knoch F, et al. The effects of clindamycin on human osteoblasts in vitro. Arch Orthop Trauma Surg 2008;128:317-23.

47. Spizek J, Rezanka T. Lincomyvin, clindamycin and their applications. App/Microbiol Biotechnol 2004;64:455-64

48. Norden CW, Shinner E, Niederriter K. Clindamycin treatment of experimental chronic osteomyelitis due to Staphylococcus aureus. J Infect Dis 1986;153:956-9.

49. Summersgill JT, Schupp LG, Raff MJ. Comparative penetration of metranidazole, clindamycin, cloraphenicol, cefoxitin, ticarcillin and moxalactam into bone. Antimicrob Agents Chemother 1982;21:601-3.

50. Kalteis T, Beckmann J, Schröder HJ, et al. Treatment of implant-associated infectious with moxifloxacin: an animal study. Int J Antimicrob Agents 2006;27:444-8.

51. Kim H, Choi SH, Ryu JJ, et al. The biocompatibility of SLA-treated titanium implants. Biomed Mater 2008;3:25011.

52. Moojen DJ, Vogely HC, Fleer A, et al. Prophylaxis of infection and effects on osseointegration using a tobramycin-periapatite coating on titanium implants: an experimental study in the rabbit. J Orthop Res 2009;27:710-16.

53. Eaninwene G 2nd, Yao C, Webster TJ. Enhanced osteoblast adhesion to drugcoated anodized nanotubular titanium surfaces. Int J Nanomedicine 2008;3:257-64.

54. Rogers-Foy JM, Powers DL, Brosnan DA, et al. Hydroxyapatite composites designed for antibiotic drug delivery and bone reconstruction: a caprine model. $J$ Invest Surg 1999;12:263-75.

55. Yamashita Y, Uchida A, Yamakawa T, et al. Treatment of chronic osteomyelitis using calcium hydroxyapatite ceramic implants impregnated with antibiotic. Int Orthop 1998;22:247-51.

56. Bourne RB. Prophylactic use of antibiotic bone cement: an emerging standard: in the affirmative. J Arthroplasty 2004;19(Suppl 1):69-72.

57. Ismael F, Bléton R, Saleh-Mghir A, et al. Teicoplanin-containing cement spacers for treatment of experimental Staphylococcus aureus joint prosthesis infection. Antimicrob Agents Chemother 2003;47:3365-7. 